\title{
Violências no Brasil: que Problemas e Desafios se Colocam à Psicologia?
}

\author{
João Paulo Pereira Barros ${ }^{1}$ \\ Luís Fernando de Souza Benicio ${ }^{1}$ \\ ${ }^{1}$ Universidade Federal do Ceará, CE, Brasil. \\ ${ }^{1}$ Universidade Federal do Ceará, CE, Brasil. \\ Pedro Paulo Gastalho de Bicalho ${ }^{1}$ \\ ${ }^{1}$ Universidade Federal do Rio de Janeiro, RJ, Brasil.
}

\begin{abstract}
Resumo: Este artigo tem como objetivo discutir problemas e desafios colocados à Psicologia por expressões da violência no Brasil, analisando suas implicações éticas na problematização de políticas de subjetivação atuantes nesses cenários. Para essa discussão sobre as expressões da violência, elegemos dois analisadores: os fenômenos do encarceramento em massa e dos homicídios de segmentos juvenis. Nos últimos anos, a Psicologia tem tomado cada vez mais o campo das violências como objeto de discussão, intervenção e produção científica. Isso se materializa fortemente pelas questões sociopolíticas do país, especialmente no que se refere às abordagens policiais, ao encarceramento em massa, ao aumento sistemático/ininterrupto dos homicídios de segmentos infantojuvenis negros, colocando em discussão políticas de aprisionamento e criminalização. Utilizaremos autores que refletem criticamente acerca da colonialidade, a exemplo de Mbembe, dialogando com produções da Psicologia Social que discutem violência. O texto se desenvolverá por meio de três seções. Na primeira, discutiremos a problemática das mortes juvenis e do encarceramento em massa como expressões de uma necropolítica à brasileira. Na segunda, problematizaremos a produção de vidas (in)vivíveis como um dos desafios éticos à Psicologia em contextos de violências. Por último, abordaremos o aceno ético necessário como caminho de construção de uma outra Psicologia.
\end{abstract}

Palavras-chave: Violências, Psicologia, Homicídios, Encarceramento, Necropolítica.

\section{Expressions of Violence in Brazil: What Problems and Challenges do They Pose to Psychology?}

\begin{abstract}
This article aims to discuss problems and challenges posed to Psychology by expressions of violence in Brazil, analyzing their ethical implications in the problematization of subjectivation policies in these scenarios. For this discussion on the expressions of violence, we chose two analysts: the phenomena of mass incarceration and homicides of juvenile segments. In recent years, Psychology has increasingly taken the field of violence as an object of discussion, intervention and scientific production. This is strongly reflected in the country's sociopolitical issues, especially with regard to police approaches, mass incarceration, the systematic / uninterrupted increase in homicides of black child and youth segments, and the questioning of policies of imprisonment and criminalization. We will use authors who reflect critically on coloniality, such as Mbembe, dialoguing with productions of Social Psychology that discuss violence. The text will be developed through three sections. In the first one, we will discuss the problem of juvenile deaths and mass incarceration as expressions of a necropolicy in Brazil. In the second, we will problematize the production of (in) livable lives as one of the ethical challenges to Psychology in contexts of violence. Finally, we will approach the necessary ethical approach as a way of building another Psychology.
\end{abstract}

Keywords: Violence, Psychology, Homicide, Incarceration, Necropolítica. 


\title{
Violencias en Brasil: ¿Qué Problemas y Desafíos se le Plantean a la Psicología?
}

\begin{abstract}
Resumen: Este artículo tiene como objetivo discutir problemas y desafíos planteados a la Psicología por las expresiones de violencia en Brasil, analizando sus implicaciones éticas en la problematización de políticas de subjetivación actuantes en esos escenarios. Para esta discusión sobre las expresiones de la violencia, elegimos dos analizadores: los fenómenos del encarcelamiento masivo y de los homicidios de segmentos juveniles. En los últimos años, la Psicología ha tomado cada vez más el campo de la violencia como objeto de discusión, intervención y producción científica. Esto se materializa fuertemente por las cuestiones sociopolíticas del país, especialmente en lo que se refiere a los abordajes policiales, al encarcelamiento masivo, al aumento sistemático/ininterrumpido de homicidios de segmentos infantojuveniles negros, poniendo en discusión políticas de aprisionamiento y criminalización. Utilizaremos autores que reflexionen críticamente acerca de la colonialidad, a ejemplo de Mbembe, dialogando con producciones de la Psicología Social que discutan violencia. El texto se desarrollará por medio de tres secciones. En la primera, discutiremos la problemática de las muertes juveniles y del encarcelamiento en masa como expresiones de una necropolítica en Brasil. En la segunda, problematizaremos la producción de vidas (in) vivibles como uno de los desafíos éticos a la Psicología en contextos de violencias. Finalmente, abordaremos el asentimiento ético necesario como una forma de construir otra Psicología.
\end{abstract}

Palabras clave: Violencias, Psicología, Homicidios, Encarcelamiento, Necropolítica.

\section{Introdução}

Este artigo visa refletir sobre problemas e desafios que as expressões da violência no Brasil colocam à Psicologia, ressaltando suas implicações éticas na problematização de políticas de subjetivação em jogo nesses cenários. A fim de tornar exequível a discussão proposta, realizaremos um recorte no campo multifacetado das expressões da violência e elegemos dois analisadores para este texto: os fenômenos do encarceramento em massa e dos homicídios de segmentos juvenis. $\mathrm{O}$ enfoque doravante nessas duas expressões da violência no Brasil, e não em outras, justifica-se por partirmos da premissa de que elas se constituem o ápice de redes e circuitos de violências relacionadas a um processo de precarização induzida a que está submetida - a partir de continuidades e descontinuidades históricas - uma ampla gama de populações pauperizadas, racializadas, subalternizadas e territorializadas.

Nos últimos anos, a Psicologia tem tomado cada vez mais o campo das violências como objeto de discussão, intervenção e produção científica. Isso se materializa fortemente pelas questões sociopolíticas do país, especialmente no que se refere às abordagens policiais, ao encarceramento em massa, ao aumento sistemático / ininterrupto dos homicídios de segmentos infantojuve- nis negros, colocando em discussão políticas de aprisionamento e criminalização (Barros, \& Benicio, 2017; Cavalcanti, Barbosa, \& Bicalho, 2018; Oliveira, Rezende, \& Bicalho, 2018; Pontes, Ferreira, \& Bicalho, 2018; Scisleski, Silva, Galeano, Bruno, \& Santos, 2016).

Para nos ajudar na problematização do encarceramento em massa, dos homicídios de segmentos infantojuvenis e das racionalidades que as produzem, utilizaremos a noção de necropolítica, apresentada pelo pensador camaronês Mbembe (2016), como operador conceitual na discussão sobre a constituição de zonas de morte e a produção de corpos matáveis. Articularemos tal discussão à problematização de Butler (2015) sobre quadros de guerra, vidas precárias e (não) passíveis de luto. Para a perspectiva mbembeana, a necropolítica se apresenta como uma tecnologia de produção e gestão da morte, constituindo-se como um indicador tático que permite analisar o campo das violências, especificamente o fenômeno do genocídio e do enclausuramento de determinados segmentos no âmbito das democracias liberais, apontando continuidade da colonialidade. Tais regimes se atualizam por intermédio de práticas de desumanização, coisificação e indignificação de determinados segmentos populacionais (Benício et al., 2018). 


\section{Mortes juvenis e Encarceramento em Massa: necropolítica e precarização da vida como modo de governo no Brasil}

Sobre o encarceramento em massa, recordaremos janeiro de 2017 com a guerra de facções criminosas em prisões brasileiras, colocando em discussão a fragilidade do sistema. Na ocasião, mais de cem presidiários foram mortos durante rebelião em Manaus (AM), Boa Vista (RR) e Alcaçuz (RN). Recentemente, dados do sistema de informação estatística do sistema penitenciário brasileiro (Infopen) apontam que o Brasil possui mais de 725 mil pessoas presas, ficando atrás apenas da China (1,6 milhão) e dos Estados Unidos (2,1 milhões) em população carcerária. Vale ressaltar, ainda, que as prisões do nosso país têm uma taxa de ocupação média de $200 \%$. Isto é, elas têm capacidade para receber somente a metade do número de pessoas presas. Além de levar o Brasil ao terceiro lugar no ranking mundial de encarceramento, esses dados nos colocam como um dos países que mais encarcera mulheres, uma vez que a população carcerária feminina cresceu 698\% no Brasil em 16 anos. Em 2000, havia 5.601 mulheres cumprindo medidas de privação de liberdade. Em 2016, o número saltou para 44.721. Apenas em dois anos, dezembro de 2014 a dezembro de 2016, tivemos um aumento de 19,6\% subindo de 37.380 para 44.721 , sendo nítido o efeito da política de "guerra às drogas" vigente no país, a qual produz tipicidade que é responsável por mais da metade do encarceramento de mulheres (Becker, Spessote, Sardinha, \& Bicalho, 2016), produzindo importantes discussões para os estudos de gênero.

Para pensar esse campo de discussão, Barros, Nunes, Sousa e Cavalcante (Prelo) ${ }^{1}$, problematizam que a construção desigual dos gêneros e das raças que potencializa a precarização dos corpos femininos, também constituem processos de criminalização. Com isso, ao olhar para a seletividade penal, surge o desafio de interseccionar nossas análises, atentando-nos para as relações entre raça, classe, gênero e geração, pois o perfil que tem prevalecido nas prisões brasileiras é de jovens negras e moradoras da periferia (Barros, Nunes, Sousa \& Cavalcante, Prelo) ${ }^{4}$.

Para complexificar o debate Borges (2018), ao tomar o encarceramento em massa como dispositivo, corrobora com a ideia de que a guerra às drogas é o pano de fundo para que o encarceramento mantenha elementos do regime escravista nos dias atuais. A autora ressalta ainda que, no mesmo período em que a população pobre, sobretudo negra, teve acesso a algumas políticas sociais e milhares de famílias não se encontravam mais em condição de pobreza extrema, essa mesma população também passa a ser o alvo de políticas criminais mais ostensivas (Borges, 2018).

Em uma análise feita por Valente (2018), pesquisador da Pastoral Carcerária, percebe-se que a tendência da problemática do encarceramento em massa é se agravar, considerando o aumento de unidades prisionais que corroboram com processos de banalização dessas instituições e de suas barbáries, respondendo, em parte, ao clamor de amplos setores sociais. Para entender esse desejo punitivo penal, Batista (2015) aponta para uma gestão policial da vida, direcionada a pobres e negros em seu cotidiano, fazendo menção às ideias de Wacquant (2001), que apresentam o deslocamento da atenção social do Estado para uma gestão penal da pobreza.

Ao aprofundarmos a racionalidade política que sustenta o sistema prisional brasileiro nos dias atuais, situamos os diálogos de Rangel e Bicalho (2016; 2017) ao afirmarem que tais números não são ao acaso, uma vez que estão em consonância com a lógica da penalidade neoliberal, dentro do sistema capitalista. Outra pista importante que conecta com as questões dos dias atuais, dialogando com Kilduff (2010), seria por conta da redução de orçamento federal na assistência social, saúde pública, educação e moradia, produzindo, como efeito direto, o incremento das funções penais e policiais do Estado sobre populações antes assistidas. E, ainda, a desarticulação da Política Nacional de Participação Social por meio do Decreto no 9.759, de 11 de abril de 2019, que "extingue e estabelece diretrizes, regras e limitações para colegiados da administração pública federal", com efeitos diretos na atuação da sociedade civil na execução das políticas públicas, incluindo a extinção do Conselho Nacional de Segurança Pública (Conasp), organizado após a primeira (e única) Conferência Nacional de Segurança Pública (Conseg) realizada no país, em 2009. Importante destacar que o Conselho Federal de Psicologia, desde a primeira eleição, sempre compôs efetivamente a constituição de tal órgão colegiado.

${ }^{1}$ Barros, J. P. P.; Nunes, L. F.; Sousa, I. S \& Cavalcante, C. O. B. (Prelo). Criminalização, extermínio e encarceramento: expressões necropolíticas no Ceará (São Paulo). Revista de Psicologia Política. 
Ao mesmo tempo em que discutimos o fenômeno do encarceramento em massa contra determinados segmentos na sociedade brasileira, pensamos também que a problematização do fenômeno da violência letal contra segmentos infantojuvenis contribuirá na cartografia de racionalidades que atravessam sistema prisional e segurança pública.

Dados relativos à questão da violência letal envolvendo segmentos infantojuvenis negros e pauperizados permitem reconhecer que os homicídios se configuram como um dos principais dispositivos de controle social de populações e territórios na contemporaneidade, torna-o um dos principais desafios ético-políticos no cenário brasileiro (Barros, \& Benicio, 2017). Dados do Atlas da Violência de 2018 apontam que, entre 1989 e 2016, foram mortas cerca de 910 mil pessoas por perfuração de armas de fogo no país. $O$ mesmo estudo descreve que até a década de 1980, a proporção de homicídios com o uso da arma de fogo girava em torno de $40 \%$. Desde então, esse índice cresceu ininterruptamente até 2003, quando atingiu a proporção de 71,1\% ficando estável até 2016. Contudo, ainda segundo o mesmo estudo, o Brasil lidera como o país com maior número de mortes oriundas de Perfuração por Arma de Fogo (PAF). As taxas de mortalidade por armas de fogo, quando caracterizadas, distribuem-se em dois grupos na sociedade brasileira: negros (40,2 por 100.000 habitantes) e não negros (16,0 por 100.000 habitantes) (IPEA, 2018).

Em 2017, segundo dados do 12a Anuário Brasileiro de Segurança Pública de 2018, foram apreendidas 119.484 armas. O combate ao comércio ilegal de arma de fogo, para os especialistas, é uma das principais estratégias para a redução dos homicídios, pois os estados onde se observou maior crescimento da violência letal na última década, são aqueles em que houve, ao mesmo tempo, maior crescimento da vitimização por arma de fogo. Aponta-se, ao mesmo tempo, a necessidade de restrição da legalidade quanto à posse e ao porte de armas de fogo no país.

Dados do Fórum Brasileiro de Segurança Pública apontam que, no ano de 2017, ocorreram 63.880 mortes violentas intencionais, significando que 175 pessoas foram mortas por dia. As maiores taxas por 100 mil habitantes concentram-se em três estados: Rio Grande do Norte $(68,0)$; Acre $(63,9)$ e Ceará $(59,1)$. Na dinâmica da violência urbana brasileira nos últimos anos, ressalta-se o processo de "nordestinação" dos homicídios, como tem observado Barros, Paiva,
Rodrigues, Silva e Leonardo (2018). Fenômeno que se observa no Índice de Homicídios na Adolescência (IHA), calculado pelo Programa de Redução de Violência Letal - PRVL, no qual oito dos dez estados com maior IHA estão no Nordeste (Melo, \& Cano, 2017).

Nesses cenários, a morte de adolescentes e jovens ganha destaque, pois, de acordo com Waiselsz (2015), entre 1980 a 2014 o aumento foi de 699,5\%. Ainda sobre essa realidade preocupante, o Atlas da Violência de 2017 aponta que mais de 318 mil jovens foram assassinados entre 2005 e 2015. Enquanto a taxa média de mortes da população geral em 2015 foi de 28,9\% por 100 mil habitantes, a da população jovem foi de $60,9 \%$ por 100 mil). Além disso, vale ressaltar outros dados, como, por exemplo, a quantidade de pessoas assassinadas por sexo: $99,3 \%$ (sexo masculino); idade: $81,8 \%$ tinham entre 12 e 29 anos e a cor: $76,2 \%$ eram negras (Fórum Brasileiro de Segurança Pública, 2017).

Assim como no dispositivo do encarceramento em massa, é fundamental trazer à tona a seletividade racial atrelada ao fenômeno dos homicídios, pois, como apresentado anteriormente, a maioria são negros e a morte de negros é crescente, diferentemente da morte de não negros, como mostra o último Atlas da Violência (IPEA, 2018). O extermínio desses segmentos, jovens negros, pobres e moradores das periferias urbanas, evidencia um corte que hierarquiza territórios que devem ser protegidos na cidade e territórios que maximizam permanentes colônias onde guerra e paz não se separam, normas jurídicas não se aplicam, a quem se refere Mbembe (2016), tais como são as favelas e os espaços de confinamento (prisões e centros educacionais). Tendo essa seletividade, tanto o encarceramento em massa, como os homicídios, respaldam-se em uma complexa e perversa produção simbólica em torno de certas juventudes negras e pobres, assujeitadas por operações de criminalização, silenciamentos e as mais diversas exclusões (Barros, Acioly, \& Ribeiro, 2016; Barros, Rodrigues, Silva \& Leonardo, 2017; Barros, \& Benicio, 2017; Benício et al., 2018).

\section{"Devir-negro do mundo", "Corpo Noturno da Democracia" e a produção de vidas (in)vivíveis: problemas éticos à Psicologia}

Diante desse mapa do plano coletivo das forças que animam as dinâmicas da violência criminal no Brasil, à Psicologia se coloca o desafio de criar/poten- 
cializar, em suas pesquisas e práticas profissionais, dispositivos que problematizem a produção psicossocial de jovens negros e inseridos nas margens urbanas como corpos matáveis. Faremos tal problematização neste tópico a partir da articulação com Butler (2015; 2018) e Mbembe $(2014 ; 2017)$. A partir dessas interlocuções, tomamos o encarceramento em massa e os homicídios de jovens como dois dos nossos principais desafios éticos e aspectos da maior relevância para analisarmos o regime político atual.

Tanto o extermínio de segmentos infantojuvenis quanto o fenômeno do encarceramento em massa são expressões do que Mbembe (2014; 2017), em sua crítica ao neoliberalismo, trata como um "devir negro do mundo". Sobre isso, o autor camaronês pontua que:

Pela primeira vez na história humana, o nome Negro deixa de remeter unicamente para a condição atribuída aos genes de origem africana durante o primeiro capitalismo (predações de toda a espécie, desapossamento da autodeterminação e, sobretudo, das duas matrizes do possível, que são o futuro e o tempo). A este novo caráter descartável e solúvel, à sua institucionalização enquanto padrão de vida e à sua generalização ao mundo inteiro, chamamos o devir-negro do mundo (Mbembe, 2014, p. 18).

Os homicídios e os aprisionamentos de existências que experimentam a condição negra, no sentido proposto por Mbembe (2014), escancaram ainda o que esse mesmo autor (Mbembe, 2017, p. 31) designa como "o corpo noturno da democracia". Mbembe (2017, p. 42) argumenta que "a história da democracia moderna é, no fundo, uma história com duas faces e, até, com dois corpos - o corpo solar, por um lado, e o corpo noturno, por outro". Dentre os principais símbolos desse corpo noturno, Mbembe (2017) frisa o império colonial, o estado escravagista, o plantation e a prisão, articulando lógicas de neutralização e exílio de grupos supérfluos.

Com essa discussão, Mbembe realça que, não obstante a narrativa oficial sobre democracia liberal ser de pacificação ante as guerras, as violências brutais e ilegais em plena democracia seguem sendo abafadas nas metrópoles, ao mesmo tempo em que continuam a ser toleradas e exteriorizadas nas colônias (ou, mais atualmente, nas periferias do capitalismo), consideradas como "não lugares", em perma- nente estado de exceção e guerra generalizada e fora dos limites da lei, alvos de desejos de extermínio e controle sob a retórica de "pacificação dos costumes" (Mbembe, 2017, p. 37).

É em meio a essa problematização dos limites da democracia liberal moderna, que teria a mesma matriz histórica da ordem colonial e imperialista, que Mbembe (2017, p. 33) também denuncia, usando os EUA como ilustração, o que ele chama de "comunidade da separação” (p. 34). Sua principal característica seria a coexistência de uma "comunidade de semelhantes", regida pela lei da igualdade, formadas por sujeitos de direitos, e uma "comunidade de não semelhantes", guiada pela lei da desigualdade. Nessa "dupla ordem", ancorada no preconceito racial, os "não semelhantes" são mantidos afastados e não usufruem da condição de sujeitos de direitos. Assim, a reflexão mbembeana nos indica que políticas da inimizade amparadas no racismo e na violência necropolítica são ameaças à plenificação de uma real democracia. Com efeito, o cenário de crescimento da violência letal contra jovens racializados e pauperizados no Brasil e o encarceramento em massa desse mesmo segmento social colocam sob suspeita nossa própria condição plenamente democrática, indicando continuidade de um ethos autoritário e de uma lógica colonial em um contexto neoliberal que maximiza a precarização da vida e autoriza a morte de existências descartabilizadas.

Conforme produções como as de Bicalho e Barbosa (2014), Pontes, Meza e Bicalho (2015), Barros et al. (2016; 2017), Benício et al. (2018) e Barros (2019), um dos principais aspectos psicossociais engendrados nesse contexto de intensificação da violência letal contra jovens periferizados, concorrendo para naturalizações e legitimações dessa violência, é a criminalização daqueles que morrem, por meio de atribuição (ou suspeição) de seu envolvimento com mercado varejista de drogas ilícitas localmente, nomeados por Zaccone $(2007$; 2015) de "acionistas do nada" e "indignos de vida”. Assim é que esses (não) sujeitos que personificam as classes perigosas (Coimbra, 2001; Costa, Couto, \& Bicalho, 2008; Melício, Geraldini, \& Bicalho, 2012), constituem-se como metáforas da violência (Sales, 2007) e emblemas da necropolítica no Brasil (Barros, 2019). Segundo Borges (2018), após a abolição, a criminalização tem sido um dos principais meios de perpetuação de racismos no Brasil.

Dialogando novamente com Mbembe (2017), com base na percepção de uma ameaça permanente 
e na reprodução do sentimento de terror, "as democracias liberais continuaram a fabricar espantalhos destinados a meter-lhes medo" (Mbembe, 2017, p.84). Por isso, a produção de um inimigo ficcional (ou ficcionalização do inimigo) no âmbito de uma necropolítica desumaniza corpos, o que justificaria seu extermínio ou sua prisão em um estado de exceção permanente. Entendido aqui como um operador psicossocial necropolítico que garante a eficácia das técnicas de fazer morrer nas colônias contemporâneas, como podem ser consideradas aqui as favelas, periferias urbanas, prisões e outros contextos privativos de liberdade, o medo em relação ao inimigo é atualizado continuamente e se converte em operador necrobiopolítico importante, haja vista que " [...] somos assombrados por espectros difusos. O suspeito, o bandido pode ser qualquer jovem que ande de camisa aberta, use boné, bermuda, chinelos e, principalmente, que seja negro [...] E, para conter essa turba, técnicas de vigilâncias são implementadas e desejadas" (Bento, 2018, p. 14).

Sobre a produção do inimigo no Brasil, é mister citar o trabalho de Batista (2003), que investiga juventude e tráfico de drogas no Rio de Janeiro, encontramos importantes elementos para entender a relação entre ficcionalização do inimigo nas periferias brasileiras contemporânea e a guerra às drogas como impulsionadora da criminalização de juventudes negras e pobres. A guerra às drogas no Brasil foi produzindo um novo inimigo social, a partir do deslocamento da figura do "terrorista" para a do "traficante". Já autores como Zaccone $(2007 ; 2015)$ apontam como essa nova figura do inimigo-traficante passa a ser cada vez mais associada a uma amplo espectro de jovens negros, vítimas de desamparo institucional e do desemprego, estereotipados como bandidos em regiões da cidade concentradas por descendentes de escravos, o que dissemina uma aceitabilidade do extermínio, em decorrência do medo e da insegurança, e uma espécie de autoritarismo sem ditadura que atinge sobretudo as juventudes que são tratadas como "bagaço-humano" (Batista, 2003, Bicalho, Barbosa \& Cunha, 2017).

No contexto da guerra às drogas e das implicações cada vez mais fortes do medo e da insegurança na produção de "subjetividades punitivo-penais" (Coimbra, \& Scheinar, 2012) e "adesões subjetivas à barbárie" (Batista, 2012), a produção dessa figura fantasmagórica do inimigo interno reitera a divisão racista entre os semelhantes (cidadãos de bem) e os não semelhantes (não cidadãos). Estes "não têm qualquer direito a ter direitos. São regidos pela lei da desigualdade. Esta desigualdade e a lei que a institui e na qual se baseia fundam-se no preconceito da raça" (Mbembe, 2017, p. 34)

Para Coimbra (2001), no final do século XIX e início do século XX pregava-se a superioridade branca, o aperfeiçoamento da raça e um posicionamento contra os negros e mestiços, a maior parte da população pobre brasileira. O discurso hegemônico, reforçado pela mídia, era o de que nas "periferias pobres" residia a violência, a criminalidade e o banditismo, associando pobreza e periculosidade.

Mbembe (2017) ressalta que a escravatura de negros é um dos primeiros exemplos de experiência (necro)biopolítica. O escravo é mantido vivo, mas num estado de lesão, em uma violenta condição, na forma de uma "morte-na-vida" (Mbembe, 2017, p. 124). Sua figura resultaria de uma tripla perda: A perda de um lar, a perda de direitos do corpo de cada um/ uma e a perda de um estatuto político.

Portanto, os homicídios e o aprisionamento de corpos negros e pauperizados não são acontecimentos isolados, senão o ápice de uma rede de violências múltiplas, cumulativas, reiteradas, vividas psicossocialmente e alicerçadas por uma matriz de dominação colonial, como retoma Mbembe (2014) das reflexões anticoloniais de Franz Fanon. Assim como diz Mbembe $(2014 ; 2017)$ em relação à "invenção do negro" e às "políticas de inimizade" na contemporaneidade, o jovem "suspeito" ou "potencialmente perigoso" é uma ficção útil, pois sua criminalização e sua consequente demonização regulam práticas sociais e institucionais de criação de "zonas de morte", espaços heterotópicos, marcados pela extraterritorialidade, exceção e exclusão, e pela aniquilação de sujeitos virtualmente perigosos que o habitam (Agier, 2015).

Diante da distinta distribuição de direito à vida no contexto brasileiro, Bento (2018) chama atenção para o fato de que Necropolítica e Biopolítica são tecnologias de poder relacionadas e articuladas. Articulando estudos de Judith Butler, Michel Foucault, Achille Mbembe e Giorgio Agamben, Bento (2018) põe em análise como o Estado participa fundamentalmente da distribuição desigual do direito à vida, apontando que o engendramento de identidades abjetas é a engrenagem principal dessa dinâmica de produção e gestão da morte que atinge, sobretudo, 
segmentos sociais racializados. Isso se daria, segundo a autora, por "um conjunto de técnicas de promoção de vida e da morte a partir de atributos que qualificam e distribuem os corpos em uma hierarquia que retira deles a possibilidade de reconhecimento como humano e que, portanto, devem ser eliminados e outros que devem viver" (Bento, 2018, p. 7).

Nesse contexto, cabe à Psicologia tomar os circuitos de violência, em específico as mortes e dos aprisionamentos de jovens no Brasil, como problemáticas transversais, afastando-se de estratégias de sujeição juvenil por vetores de criminalização, culpabilização, segregação e silenciamento e contribuindo para a articulação de redes intersetoriais. Esse direcionamento tem uma importante significação ética e política, haja vista que o silenciamento de populações das margens urbanas é uma das marcas atuais da colonialidade como forma de negação sistemática do outro e de sua humanidade. O silenciamento imposto pela colonialidade, diz Mbembe (2014, p. 189), confina essas existências à "esfera da aparição nua: quer como refugo e resíduo, quer como esvaziado de qualquer conteúdo".

À Psicologia compete ainda a problematização das políticas de precarização da vida dos segmentos juvenis a partir de enquadramentos que os tratam, de maneira estigmatizadas, como não cidadãos. Essa precarização da vida, em âmbito macro e micropolítico, tem sido produzida numa relação entre o avanço do neoliberalismo e o crescimento de desigualdades, relação esta que se ancora em pontos como o individualismo, a indiferença ao coletivo, a fragmentação, segregação, exclusão de jovens periféricos como aspecto característico da organização dos modos de viver na/a cidade. Além disso, outros pontos em que se ancoram essas políticas de precarização da vida de juventudes marginalizadas tem sido a produção do medo e do ódio como afetos centrais na necrobiopolítica cotidiana, fazendo com que a vida do outro valha muito pouco ou nada valha, bem como a produção de modos de subjetivação segundo os quais os jovens devem se portar como empresários de si mesmo, sendo seu eventual fracasso de sua própria responsabilidade.

Sob esse prisma analítico, a precarização da vida e a produção da morte são pontos fulcrais e interligados de lógica de governamentalização contemporânea, atingindo mais fortemente certos grupos juvenis, articulando o diagrama do desempenho, a coloniali- dade e o conservadorismo em uma complexa governamentalidade neoliberal que moleculariza a lógica de mercado, espraiando-a aos diversos domínios da vida, inclusive o da produção de subjetividades, tendo como um de seus efeitos a objetificação, instrumentalização, mercantilização e descartabilidade de certas existências. Isto é, temos uma produção assimetricamente maximizada dessa precarização da vida e uma instrumentalização da morte, a partir de marcadores de raça, gênero, classe, geração e território, chegando ao extermínio juvenil em muitos casos, ao passo que os corpos juvenis (sobre)viventes são incitados cada vez mais ao desempenho nessa política de precarização. Isso remete à dimensão interseccional da vulnerabilidade, tal como discutida por Butler (2015), a qual faz com que alguns sofrimentos não sejam lamentados, se tornem invisibilizados e algumas vidas sejam abreviadas nessa política de precarização da vida como condição de governamentalidade necrobiopolítica, no bojo histórico-social da perpetuação da colonialidade, do patriarcado e do autoritarismo, que, inclusive, operam como vetores de produção de subjetividades na atualidade. Ademais, não é só o lugar da Psicologia na gestão das vidas precarizadas que merece ser posto em análise, mas também a própria precarização dos trabalhadores sociais no âmbito do desmonte de políticas públicas voltadas às vidas precarizadas.

Se, como ponto de partida de sua discussão sobre precariedade com vistas a uma nova ontologia corporal, Butler (2015) considera que toda vida é precária, visto que sua sobrevivência depende invariavelmente de suportes coletivos, pelo menos duas questões nos são muito caras e nos possibilitam conectar os debates sobre precariedade e necropolítica: que condições, conjuntos de forças, arranjos políticos e processos psicossociais tornam certos corpos matáveis? A partir de que operações de poder suas vidas são desabilitadas por não serem reconhecidas propriamente como vidas (que importam)?

Pensando a produção de corpos vivíveis e matáveis, com base em agenciamentos entre as reflexões de Butler e Mbembe, chegamos ao seguinte ponto: para entendermos como se estabelece uma necropolítica à brasileira, caracterizada pela produção e gestão da morte a partir da suspensão da humanidade de certas existências, é necessário por em análise o estatuto político de determinadas vidas, já que, ao não serem reconhecidas como vidas efetivamente humanas, mas 
sim como identidades abjetas, nem todas são consideradas passíveis de luto e dignas de usufruir de um dos direitos humanos fundamentais: 0 direito à vida.

Para Benicio et al. (2018) uma das pilastras da ordem capitalística atual, a despeito dos mitos de democracia racial, passa a ser a produção/gestão de certas zonas de morte juntamente com certos corpos matáveis. Neste regime, como denuncia Mbembe (2017), a cidadania ainda é produzida por exclusão, como privilégio de alguns, e não um direito de todos e todas. Logo, é necessária a construção de zonas de morte nas "periferias", produzindo a própria territorialidade periférica como um "não lugares", para que a vida do "centro" seja viabilizada como um privilégio.

Butler (2015) se dedica a refletir sobre como a guerra designa determinadas populações como não passíveis de luto. Já Mbembe (2014), em sua "crítica à razão negra", aponta como a guerra foi e continua sendo um princípio fundamental para a dominação colonial. Um dos efeitos das maquinarias de guerra nas tramas da violência no Brasil, tais como o paradigma da guerra às drogas, tem o agenciamento de certos modos de sujeição que constituem certos segmentos como matáveis, corpos que devem ser combatidos, e outros corpos vivíveis, que devem ser protegidos, alguns dos quais, assujeitados pelo medo, constituem-se como corpos que, como condição para sua segurança, alimentam o que Mbembe (2017) chama de desejo de inimigo, desejo de apartheid e desejo de extermínio. Fanon, em Os Condenados da Terra (1968), aponta que:

O mundo colonizado é um mundo cortado em dois. A linha de corte, a fronteira, é indicada pelas casernas e pelos postos policiais. Nas colônias, o interlocutor legítimo e institucional do colonizado, o porta-voz do colono e do regime de opressão é o policial ou o soldado. Nas sociedades de tipo capitalista, o ensino, religioso ou leigo, a formação dos reflexos morais e transmissíveis de pai para filho, a honestidade exemplar de operários condecorados depois de cinquenta anos de bons e leais serviços, o amor estimulado à harmonia e à sabedoria, essas formas estéticas do respeito à ordem estabelecida, criam em torno do explorado uma atmosfera de submissão e de inibição que alivia consideravelmente a tarefa das forças da ordem. Nos países capitalistas, entre o explorado e o poder interpõe-se uma multidão de pro- fessores de moral, de conselheiros, de "desorientadores". Nas regiões coloniais, em contrapartida, o policial e o soldado, por sua presença imediata, suas intervenções diretas e frequentes, mantêm o contato com o colonizado e lhe aconselham, com coronhadas ou napalm, que fique quieto. Como vemos, o intermediário do poder utiliza uma linguagem de pura violência. $\mathrm{O}$ intermediário não alivia a opressão, não disfarça a dominação. Ele as expõe, ele as manifesta com a consciência tranquila das forças da ordem. O intermediário leva a violência para as casas e para os cérebros dos colonizados (1968, p. 28).

Desse modo, outro agenciamento Butler-Mbembe é o seguinte: para fazer frente à necropolítica, há que se investir na reinvenção do próprio estatuto ontológico da vida como uma de nossas principais tarefas ético-políticas. Faz-se necessário investir numa noção de humanidade e, logo, de direitos humanos, em que caibam e importem todos e todas nós, e não só certos humanos, o que implica desmontar maquinarias de produção de subjetividades truculentas e alterofóbicas, um dos efeitos simbólicos da necropolítica.

Por conseguinte, a discussão sobre vidas (não) passíveis de luto leva à reflexão sobre a regulação da comoção, pela mídia e pelos discursos oficiais:

Se aceitarmos que a comoção é estruturada por esquemas interpretativos que não compreendemos inteiramente, isso pode nos ajudar a entender por que sentimos horror diante de certas perdas e indiferença ou mesmo justeza diante de outras? [...] Quando uma população parece constituir uma ameaça direta à minha vida, seus integrantes não aparecem como "vidas", mas como uma ameaça à vida (Butler, 2015, p. 68-69).

Tanto Butler (2015) quanto Mbembe (2017) nos ajudam a pensar que outro efeito psicossocial e político das maquinarias de guerra, além da hierarquização das vidas, é a diminuição de sentimentos de interdependência e a produção de uma noção cada vez mais restritiva do que seria um "nós". Em um dos trechos de sua discussão, Butler (2015, p. 71) é precisa quanto a isso:

A guerra procura negar as formas irrefutáveis e contínuas pelas quais todos estamos submetidos uns aos outros, vulneráveis à destruição pelo 
outro e necessitados de proteção mediante acordos globais e multilaterais baseados no reconhecimento de uma precariedade compartilhada. [...] O sujeito que sou está ligado ao sujeito que não sou, que cada um de nós tem o poder de destruir e de ser destruído, e que estamos unidos uns aos outros nesse poder e nessa precariedade. Nesse sentido, somos todos vidas precárias (p. 71)

Sob a inspiração do diálogo com Butler (2015), é justamente a alocação diferencial dessa condição precária, a qual é maximizada para uns e minimizadas para outros/as, que pode ser o ponto de partida para as discussões éticas sobre os saberes e fazeres em Psicologia no Brasil atual. Em um contexto necropolítico de produção massificada e espetacularizada de mortes de corpos invivíveis, perversamente (in)visíveis e não enlutáveis, o que pode ser posto em questão, no âmbito das pesquisas e práticas profissionais em Psicologia, em aliança com corpos que lutam pela viabilização de vidas vivíveis, são as possibilidades de mudança dos próprios termos da condição de ser reconhecido/a e a construção de condições mais igualitárias e democráticas de reconhecimento e compartilhamento da precariedade que constitui a todos e todas nós. Para a Psicologia, afirmar em suas práticas que todas as vidas importam é um aceno ético a ser conectado ao fortalecimento de um regime efetivamente democrático e à reivindicação política de condições que tornem a vida dos mais diversos segmentos infantojuvenis plenamente sustentável e viável.

\section{Vidas importam: caminhos para uma outra Psicologia}

O aceno ético é afirmado sob inspiração de Martin-Baró (2006), ao nos recomendar que a Psicologia latino-americana deve descentrar sua atenção de si mesma. É necessário que assumamos um projeto que vise colocarmos em segundo plano o debate do status científico da Psicologia, ao propormos perspectivas diferenciadas e críticas a partir dos problemas reais dos nossos povos (Cidade, \& Bicalho, 2019). É a isso que Martin-Baró (2006) denomina de potencialização da virtude dos povos, o que implica certos caminhos ético-políticos para as práticas de pesquisa em Psicologia: "[...] a necessidade objetiva das maiorias latino-americanas se constitui na sua libertação histórica de estruturas sociais de opressão e colonização, que mantém seus povos subjugados; é exatamente nisso que a Psicologia deve focar suas preocupações e esforços" (p. 11).

A importância ética da ideia de potencialização dos povos implica que aprendamos a ler a realidade circundante e a (re)escrevermos nossa própria história. Surge daí a necessidade, a partir da articulação com Martin-Baró, de examinarmos não apenas o que somos enquanto sujeitos, coletivos e nação, mas o que poderíamos ter sido sob outras condições sociais, e talvez o mais importante, o que deveríamos e devemos ser frente às necessidades de nossos povos (Martin-Baró, 2006).

As lutas latino-americanas apontam para a necessidade primordial de descolonização dos saberes, das práticas e da gestão da população. É necessário que protagonizemos a produção de saberes críticos sobre nós mesmos, sobre o mundo e sobre os modos de inserção e vinculação com a pesquisa. Nesse sentido, é imprescindível que a Psicologia tome esse movimento como possibilidade de outras direções ético-metodológicas, capazes de possibilitar a produção e circulação de histórias, laços e narrativas, visando a transformação das condições sociais seculares do país. Em seu projeto de Psicologia Social Crítica, Silvia Lane aposta na necessidade de explicitar os vínculos com os interesses dominantes e de redirecionar as produções psicológicas nos sentidos de contribuição para a transformação social (Bock, Ferreira, Gonçalves, \& Furtado, 2007).

Tomar a potencialização dos povos e as lutas por democracia e o enfrentamento da desigualdade como horizonte ético-político de formação, produção de conhecimento e práticas em Psicologia produz uma fissura monumental nas diretrizes e bases da Psicologia enquanto ciência moderna e europeia. É necessária uma outra concepção de sujeito para a Psicologia: um sujeito social e histórico, como nos propôs Silvia Lane (Bock et al., 2007).

Portanto, se aspiramos acenos éticos junto ao desafio de problematizarmos as violências no Brasil a partir da produção da pesquisa em Psicologia, precisamos romper com nossos próprios processos de exploração e colonização do pensamento e das reflexões psicológicas. Efetivar o deslocamento de uma historicidade naturalizada e imutável, das ideologias dominantes que defendem os privilégios de uma minoria da população e da naturalização das contradições e desigualdades sociais. E, deste modo, possibilitar a viabilização de vidas que importam. Vidas, de fato, vivíveis. 


\section{Referências}

Agier, M. (2015). Do refúgio nasce o gueto: antropologia urbana e política dos espaços precários. In S. S. Carneiro, P. Birman, C. Machado, \& M. P. Leite (Orgs.), Dispositivos urbanos e a trama dos viventes: Ordens e resistências (pp. 33-54).Rio de Janeiro: FGV Editora.

Barros, J. P. P. (2019). Juventudes desimportantes: A produção psicossocial do "envolvido" como emblema de uma necropolítica no Brasil. In: V. F. R. Colaço, I. M. P. Germano, L. L. Miranda, \& J. P. P. Barros (Org.), Juventudes em movimento: Experiências, redes e afetos. Fortaleza, CE: Expressão.

Barros, J. P. P., Acioly, L. F., \& Ribeiro, J. A. D. (2016). Re-tratos da juventude na cidade de Fortaleza: Direitos humanos e intervenções micropolíticas. Revista de Psicologia, 7(1), 115-128.

Barros, J. P. P. \& Benício, L. F. S. (2017). “Eles nascem para morrer”: uma análise psicossocial da problemáticas dos homicídios de jovens em Fortaleza. Revista de Psicologia, 8(2), 34-43. https://doi.org/10.1590/1982-3703002892017

Barros, J. P. P., Benício, L. F. S., Silva, D. B., Leonardo, C. S., \& Torres, F. J. P. (2017). Homicídios juvenis e os desafios à democracia brasileira: Implicações ético-políticas da psicologia. Psicologia: Ciência e Profissão, 37(4), 1051-1065. https://doi.org/10.1590/1982-3703002892017

Barros, J. P. P., Paiva, L. F. S., Rodrigues, J. S., Silva, D. B., \& Leonardo, C. S. (2018). “Pacificação” nas periferias: Discursos sobre as violências e o cotidiano de juventudes em Fortaleza. Revista de Psicologia, 9(1), 117-128.

Batista, V. M. (2003). Difíceis ganhos fáceis. Rio de Janeiro, RJ: Revan.

Batista, V. M. (2015). A juventude e a questão criminal no Brasil. In: Magalhães, J. L.Q., Salum, M. J. G., \& Oliveira, R. T. Por que somos contrários à redução da maioridade penal? Brasília, DF: Conselho Federal de Psicologia.

Batista, V. M. (2012). Adesão subjetiva à barbárie. In V. M. Batista (Org.), Loïc Wacquant e a questão penal no capitalismo neoliberal. Rio de Janeiro, RJ: Revan.

Becker, A., Spessote, D. V., Sardinha, L.S., \& Bicalho, P. P. G. (2016). O cárcere e o abandono: Prisão, penalização e relações de gênero. Psicologia, Diversidade e Saúde, 5(2), 141-154. https://doi.org/10.17267/2317-3394rpds.v5i2.1050

Benício, L. F. S., Barros, J. P. P., Rodrigues, J. S., Silva, D. B., Leonardo, C. S., \& A. F. Costa. (2018). Necropolítica e Pesquisa-intervenção sobre homicídios de adolescentes e jovens em Fortaleza, CE. Psicologia: Ciência e Profissão, 38 (n.spe.2), 192-207. https://doi.org/10.1590/1982-3703000212908

Bento, B. (2018). Necrobiopoder: Quem pode habitar o Estado-nação? Cadernos Pagu, (53), 1-16. https://doi.org/1 $0.1590 / 18094449201800530005$

Bicalho, P. P. G., \& Barbosa, R. B. (2014). O modo indivíduo nas políticas públicas sobre drogas no Brasil e as encomendas endereçadas à Psicologia. Polis e Psique, 4(2), 230-249. https://doi.org/10.22456/2238-152X.51096

Bicalho, P. P. G., Barbosa, R. B., \& Cunha, T. C. (2017). Os desafios do setor segurança pública para a formação em álcool e outras drogas baseada nos direitos humanos In M. D. Vecchia, T. M. Ronzani, S. T. Paiva, C. B. Batista, \& P. H. A. Costa, Drogas e direitos humanos : Reflexões em tempos de guerra às drogas (pp. 187-208). Porto Alegre, RS: Rede Unida.

Bock, A. M. B., Ferreira, M. R., Gonçalves, M. G. \& Furtado, O. (2007). Silvia Lane e o projeto do "Compromisso Social da Psicologia”. Psicologia \& Sociedade, 2 (n.spe.), 46-56. https://doi.org/10.1590/S0102-71822007000500018

Borges, J. (2018). O que é encarceramento em massa?.Belo Horizonte, MG: Letramento: Justificando.

Butler, J. (2018). Corpos em aliança. Rio de Janeiro, RJ: Civilização Brasileira.

Butler, J. (2015). Quadros de guerra: Quando a vida é passível de luto. Rio de Janeiro, RJ: Civilização Brasileira.

Cavalcanti, C. S., Barbosa, R. B., \& Bicalho, P. P. G. (2018). Os tentáculos da tarântula: Abjeção e necropolítica em operações policiais a travestis no Brasil pós-redemocratização. Psicologia: Ciência e Profissão, 38(n.spe.2), 175191. https://doi.org/10.1590/1982-3703000212043

Cidade, M. L. R., \& Bicalho, P. P. G. (2019). É possível libertar a Psicologia? Caminhos em direção a psicologias da libertação. In: N. M. F. Guareschi (Org.), Psicologia e assistência social (pp. 36-51). Petrópolis, RJ: Vozes.

Coimbra, C. M. B. (2001). Operação Rio: O mito das classes perigosas. Rio de Janeiro, RJ: Intertexto.

Coimbra, C. M. B., \& Scheinvar, E. (2012). Subjetividades punitivo-penais. In:V. M. Batista (Org.), Loic Wacquant e a questão penal no capitalismo neoliberal. Rio de Janeiro, RJ: Revan. 
Costa, R. C., Couto, J. D. \& Bicalho, P. P. G. (2008). Psicologia e políticas de segurança pública: o analisador 'Caveirão'. Psico, 39(4), 10.

Decreto n 9.759, de 11 de abril de 2019 (2019). Extingue e estabelece diretrizes, regras e limitações para colegiados da administração pública federal. Brasília. 2019. Recuperado em 20 de julho, 2019, de http://www.in.gov.br/ materia//asset_publisher/Kujrw0TZC2Mb/content/id/71137350/dole-2019-04-11-decreto-n-9-759-de-11-deabril-de-2019-71137335

Fanon, F. (1968). Os condenados da terra. Rio de Janeiro, RJ: Civilização Brasileira.

Fórum Brasileiro de Segurança Pública. (2017). 11º Anuário Brasileiro de Segurança Pública. São Paulo: o autor.

Instituto de Pesquisa Econômica Aplicada - IPEA. (2018). Atlas da violência. Rio de Janeiro, RJ: o autor.

Kilduff, F. (2010). O controle da pobreza operado através do sistema penal. Katálysis, 13(2), 240-249. https://doi. org/10.1590/S1414-49802010000200011

Martin-Baró, I. (2006). Hacia una psicologia de la liberación. Revista Electrônica de Intervención Psicosocial y Psicología Comunitária, 1(2), 7-14.

Mbembe, A. (2014). Crítica da razão negra. Lisboa: Antígona.

Mbembe, A. (2016). Necropolitica. Arte e Ensaios, (32), 123-151.

Mbembe, A. (2017). Políticas da inimizade. Lisboa: Antígona.

Melicio, T. B. L., Geraldini, J. R., \& Bicalho, P P .G.. (2012). Biopoder e UPPs: Alteridade na experiência do policiamento permanente em comunidades cariocas. Fractal: Revista de Psicologia, 24(3), 599-622. https://doi. org/10.1590/S1984-02922012000300011

Melo, D. L. B., \& Cano, I. (2017) I. Índice de homicídios na adolescência: IHA 2014. Rio de Janeiro, RJ: Observatório de Favelas.

Oliveira, M. F., Rezende, R. A. S. S., \& Bicalho, P. P. G. (2018). Direitos humanos, segurança pública e a produção do medo na contemporaneidade. Cadernos Brasileiros de Saúde Mental, 10(25), 118-140.

Pontes, A. K, Ferreira, A. A. L. \& Bicalho, P. P. G. (2018). Uma história da internação de ébrios, alcoolistas e vadios durante a Primeira República: lições para as políticas atuais?. Revista de psicología (Santiago), 27(2), 127-144.

Pontes, A. K., Meza, A. P. S., \& Bicalho, P. P. G. (2015). Ciência e política das drogas: as controvérsias em torno das políticas públicas de internação compulsória. Estudos e Pesquisas em Psicologia, 15(4), 1433-1450.

Rangel, F. M., \& Bicalho, P. P. G. (2017). O alongamento do tempo de prisão e a violação de direitos na custódia de presos no Brasil. Avances en Psicología Latinoamericana, 35(3), 473-483.

Rangel, F. M., \& Bicalho, P. P. G. D. (2016). Superlotação das prisões brasileiras: Operador político da racionalidade contemporânea. Estudos de Psicologia (Natal), 21(4), 415-423.

Scisleski, A. C. C., Silva, J. L. C., Galeano, G. B., Bruno, B. S., \& Santos, S. N. (2016). Racismo de Estado e tanatopolítica: reflexões sobre os jovens e a lei. Fractal: Revista de Psicologia, 28(1), 84-93.

Valente, R. A.. (2018) A luta antiprisional no mundo contemporâneo: um estudo sobre experiências de redução da população carcerária em outras nações. São Paulo: Pastoral Carcerária.

Waisel sz, J. J. (2015). Violência letal contra as crianças e adolescentes do Brasil. Brasília, DF: Flacso.

Zaccone, O. (2007). Acionistas do nada: quem são os traficantes de drogas. Rio de Janeiro: Revan, 2.

Zaccone, O. E. F. (2015). Indignos de vida: a forma jurídica da política de extermínio de inimigos na cidade do Rio de Janeiro. Rio de Janeiro, RJ: Revan.

João Paulo Pereira Barros

Professor Adjunto do Departamento de Psicologia e do Programa de Pós-Graduação em Psicologia da Universidade Federal do Ceará (UFC). Fortaleza - CE. Brasil.

E-mail: joaopaulobarros07@gmail.com

(iD https://orcid.org/0000-0001-7680-576X 


\section{Luís Fernando de Souza Benicio}

Professor do curso de Psicologia da Universidade Estadual do Ceará. Fortaleza - CE. Brasil.

E-mail: luisf.benicio@gmail.com

iD https://orcid.org/0000-0002-0765-2568

Pedro Paulo Gastalho de Bicalho

Professor Associado do Instituto de Psicologia da Universidade Federal do Rio de Janeiro (UFRJ). Rio de Janeiro RJ. Brasil.

E-mail: ppbicalho@gmail.com

iD https://orcid.org/0000-0003-1986-4338

Endereço para envio de correspondência:

Av. da Universidade, 2762, Benfica. Área 2 do Centro de Humanidades - Bloco Didático Prof. Ícaro de Sousa Moreira. CEP: 60.020-180. Fortaleza - CE. Brasil.

Recebido:24/06/2019

Aceito: 22/07/2019

Received:06/24/2019

Approved: 07/22/2019

Recibido:24/06/2019

Aceptado: 22/07/2019

Como citar: Barros, J. P. P., Benicio, L. F. S., \& Bicalho, P. P. G. (2019). Violências no Brasil: Que problemas e desafios se colocam à Psicologia?. Psicologia: Ciência e Profissão, 39(n.spe 2), 33-44. https://doi.org/10.1590/1982-3703003225580

How to cite: Barros, J. P. P., Benicio, L. F. S., \& Bicalho, P. P. G. (2019). Expressions of violence in Brazil: What problems and challenges do they pose to Psychology?. Psicologia: Ciência e Profissão, 39(n.spe 2), 33-44. https://doi.org/10.1590/1982-3703003225580

Cómo citar: Barros, J. P. P., Benicio, L. F. S., \& Bicalho, P. P. G. (2019). Violencias en Brasil: ¿Qué problemas y desafíos se le plantean a la Psicología?. Psicologia: Ciência e Profissão, 39(n.spe 2), 33-44. https://doi.org/10.1590/1982-3703003225580 